\title{
Immediate Clinical Outcome of 600 Cases of Percutaneous Coronary Intervention (PCI)
}

\author{
MJ UDDIN ${ }^{1}$, KS HUSSAIN $^{2}$, M ALI $^{3}$, AHK CHOWDHURY $^{3}$, SAHAQUE $^{4}$, MS RAHMAN $^{2}$, F RAHMAN $^{5}$, AR \\ $\mathrm{KHAN}^{2}, \mathrm{M} \mathrm{SAIFULLAH}^{6}, \mathrm{~A} \mathrm{SARWAR}^{6}, \mathrm{~S} \mathrm{RAHMAN}^{7}, \mathrm{MK} \mathrm{AHMED}^{8}$
}

\begin{abstract}
:
This is an ongoing study done in National Institute of Cardiovascular Diseases (NICVD) during the period April 2002 to October 2007, few cases were done in Eurobangla Heart Hospital, Lab Aid Cardiac Hospital \& National Heart Foundation, SSMC \& MH, Metropolitan Medical Center. Total number of study population was 600 with male 550 \& female 50. Indication of Percutaneous coronary intervention (PCI) was- Unstable angina (with no prior myocardial infarction) 240 cases, MI inferior (with post Myocardial infarction angina) 204 cases \& MI anterior (with post MI angina) 156 cases. The risk factors were Hypertension (HTN) 310 cases (52\%), smoking 426 cases (71\%), Diabetes Mellitus (DM) 180 cases (30\%), Positive family history for ischemic heart diseases (IHD) 120 cases (20\%), Hyperlipidemia 150 cases (25\%). Total number of target coronary arteries was 760 and total number of lesion was 803 of which780 lesions treated. Distribution of 803 lesions were left anterior descending coronary artery (LAD) 389 (proximal LAD 152, mid LAD 177, distal LAD 60), Right coronary artery (RCA) 230 (proximal 94, mid RCA 93, Distal RCA 26, RCA PD 17), Left circumflex coronary artery (LCX) 137 (proximal LCX 60, mid LCX 54, distal LCX 16, LCX PD 07), diagonal 15, obtuse marginal (OM) 20, ramus intermedius $^{12}$.

Angiographic diagnosis of the patients were Single vessel disease 312 (52\%), Double vessel disease 156 (26\%) \& Triple vessel disease 132 (22\%). Number of lesions treated were 803 of which 780 lesions was treated. PTCA with stenting done in 725 lesion \& 34 lesions treated with plain PTCA. Total occlusion was treated in 85 cases. The native vessel has a mean reference diameter was $3.03 \pm 0.61 \mathrm{~mm}$. Residual stenosis after deploying stents was $<10 \%$. Our success rate was-angiographic success $96 \%$, procedural success $94 \%$ \& clinical success $92 \%$. Total mortality was 03 . One patient having triple vessel disease died on $P$ the procedure due to sudden cardiac arrest due to asystole,

1. Dr. MJ Uddin, Associate Professor, SSMC

2. Dr. KS Hussain, Dr. MS Rahman, Dr. AR Khan², Assistant Professor, SSMC

3. Dr. M Ali, Dr. AHK Chowdhury, Professor NICVD

4. Prof. SA Haque, Professor SSMC

5. Dr. F Rahman, Associate Professor, UCC, BSMMU

6. Dr. M Saifullah, Dr. A Sarwar, Medical Officer, SSMC

7. Prof. S Rahman, Professor Emeritus

8. Dr. Md. Khurshed Ahmed, Assistant Professor, UCC, BSMMU Address of Correspondence to : Dr. MJ Uddin, Associate Professor, SSMC
\end{abstract}

one pt died on the table due to acute closure by thrombus \& one patient died on $4^{\text {th }}$ day due to huge retroperitoneal hemorrhage \& shock. Sub acute stent thrombosis occurs in 3 cases causing acute myocardial infarction \& one case required emergency CABG.

Following procedure, in hospital course of the patients were uneventful. All the patients were discharged by three to fourth day of the procedure with improvement of their clinical condition. So the result of our study is good both in plain PTCA group \& PTCA + stent group.

(University Heart Journal 2007; 3 : 50-56)

Introduction:

Coronary angioplasty was first introduced by Andreas Gruentzig in 1977 as a non-surgical method for coronary arterial revascularisation ${ }^{1}$. Fundamentally the technique involved advancing a balloon tipped catheter to an area of coronary narrowing, inflating the balloon \& then removing the catheter following deflation. Early reports demonstrated that balloon angioplasty could reduce the severity of coronary stenosis \& diminish or eliminate objective \& subjective manifestations of myocardial ischemia ${ }^{2-4}$. Though angioplasty is clearly feasible \& effective, the scope of doing coronary angioplasty was quite narrow. Angioplasty could result in sudden arterial occlusion \& subsequently myocardial infarction (MI), so immediate access to coronary bypass surgery was essential ${ }^{5}$. However with experience \& time, the cognitive $\&$ technical aspects used to perform angioplasty could be applied to a broad groups of coronary patients with higher rate of success \& lower rates of complications when compared to initial experience ${ }^{6-7}$. More than 5,00000 PCI procedures are performed yearly in the $\mathrm{US}^{8} \&$ it has been estimated that more than $10,00,000$ procedures are performed annually worldwide.

\section{Definition of PCI:}

Percutaneous coronary interventions (PCI) are an important group of technologies. Although initially PCI was limited to balloon angioplasty \& termed percutaneous transluminal coronary angioplasty (PTCA), now includes 
other new techniques capable of relieving coronary narrowing. The following are the component of PCI-Implantation of intracoronary stents, rotational atherectomy, directional atherectomy, extraction atherectomy, laser angioplasty \& other catheter devices for treating coronary atherosclerosis. In this context PTCA will be used to refer to those studies using primarily balloon angioplasty while PCI will refer to the broader group of percutaneous technologies. These new technologies influenced the effectiveness \& safety profile of initially established balloon angioplasty.

\section{Methods \& Material:}

During the period of April 2002 to October 2007, 600 Patients underwent PCI of which 500 Patients in NICVD, 14 Patients in Eurobangla Heart Hospital, 20 Cases in Lab Aid Cardiac Hospital, 30 cases in Metropolitan Medical Centre, 30 cases in Al-Helal Heart Hospital \& 2 Patients in NHF, Dhaka. \& 4 cases in SSMC \& MH Dhaka.

The Indication of PCI were unstable angina, Post myocardial infraction angina of variable duration (Table1). The age range of the patients were from $29 \mathrm{yrs}$ to 81 years with a mean of $50.50 \pm 8.69 \mathrm{yrs}$. Of the six hundred patients 50 female $\& 550$ male with a male female ratio of 11:1 Inclusion Criteria were symptomatic coronary artery disease of angina NYHA class II to IV of both sexes, having no age limitation. The risk factors were hypertension 52\% (310 cases), Smoking $71 \%$ (426 cases), Diabetes Mellitus $30 \%$ (180 cases), Dyslipidaemia 25\% (150 cases), and positive family history of ischemic heart disease $20 \%$ (120 cases). Left ventricular ejection fraction (EF) was as low as $29 \%$ with a mean of $41 \pm 12.5 \%$.

Out of 600 patients number of diseased coronary artery was 760 , of which target lesion was 803 . Stent was deployed in 725 lesions of 660 coronary arteries. Plain balloon angioplasty was done in 34 cases. Mean Coronary artery diameter was $3.03 \pm 0.61 \mathrm{~mm}$. No stent was deployed if vessels caliber less than $2.25 \mathrm{~mm}$ or lesion length $>34 \mathrm{~mm}$, in cases of extreme tortuousity and with large thrombus at the site of the lesion.

\section{Procedure:}

Angioplasty was done as elective $\&$ adhoc basis. Almost all of the procedures were done through right femoral arterial approach, except few cases done by right radial approach, in most cases as single wall puncture technique using $7 \mathrm{~F} \& 6 \mathrm{~F}$ guiding catheters most frequently Judkins type, in some cases with Extra back up catheters, Voda catheters, Amplatz left \& right catheters with premedications of aspirin, clopidogrel \& heparin in some cases. During the beginning of procedure an IV bolus of 10,000 units heparin was given followed by 5000 unit hourly \& ACT was maintained around $300 \mathrm{sec}$ during the whole procedure. In most of the cases (70\%) the lesions were predilated by stent balloons except few cases of chronic total occlusion \& heavily calcified lesion which required $1.5 \mathrm{~mm}$ new balloon $\&$ graded dilatation was done before deploying stents. Balloon expandable stents were used in/ all the cases. Femoral sheaths were removed within 4-6 hours of the procedure. Following procedure heparin was not used except multivessel angioplasties, complex lesions, chronic total occlusions, minor edge dissections. Clopidogrel was used in all patients $150 \mathrm{mg}$ daily. During hospital discharge all patients were prescribed with aspirin $150 \mathrm{mg}$ daily, Clopidogrel $150 \mathrm{mg}$ daily \& other anti ischemic therapy as required.

\section{Result :}

Our total study population was 600 with age range 29-81 years mean $50.50 \pm 8.69$ yrs. 550 patients were male \& 50 female (Table-1). Risk factors were HTN 52\%, DM 30\%, smoking $71 \%$, Hyperlipidemia $25 \%$, positive family history $20 \%$. Clinical diagnosis of patients was unstable angina without prior MI $40 \%$ post MI angina $60 \%$ (anterior MI with post MI angina $26 \%$ \& inferior MI with post MI angina $34 \%$ ). Angiographic diagnosis was single vessel disease $52 \%$ double vessel disease $26 \%$ \& triple vessel disease $22 \%$. Out of 600 patients, in 15 cases wire not passed, in 5 cases PTCA wire was negotiated but the PTCA balloon did not cross the lesion, in 3 cases wire negotiated, balloon passed \& lesion dilated but stent did not cross lesions, in one case wire crossed, balloon passed \& lesion dilated but no TIMI flow improvement, so considered as failed PTCA.

All the stents were implanted successfully except two in our initial experience. First one was a bare stent mounted on a $2.5 \times 15 \mathrm{~mm}$ balloon \& the stent was embolized in , the mid LCX \& subsequently CABG was done in that particular case. Second one was a case of $70 \%$ Proximal LAD lesion that was predilated. Then $3.0 X 9 \mathrm{~mm}$ stent passed through the lesion. Stent was inflated twice at 8-10 atm. But stent did not inflated, and then we decided to take out the stent. Accordingly stent was pulled back but did not come back; it is dislodged in the LAD at ostium. 
Then we passed a $1.5 \mathrm{~mm}$ new balloon through the stent and pushed the stent to the proper site of lesion, inflated up to $20 \mathrm{~atm}$. Again a $2.5 \mathrm{~mm}$ balloon passed through the stent and inflated up to $16 \mathrm{~atm}$. Finally 3.0 x $10 \mathrm{~mm}$ balloon passed through the stent and inflated up to 16 atmosphere and the stent was matched appropriately both proximally and distally.

Intracoronary stents were implanted in LAD 381 (Proximal LAD 156, mid LAD 176, distal LAD 49), LCX 145, (Proximal LCX 66, mid LCX 59, distal LCX 11, LCX PD 09), RCA 221 (Proximal RCA 95, mid RCA 92, distal RCA 19, RCA PD 15) OM 20, Diagonal 18, Ramus Intermedius 10. Out of 600 patients target coronary artery was 760 having 803 lesions treated (Table-II). Out of 803 lesions treated PTCA with stenting done in 725 lesions \& plain PTCA done in 34 lesions. Total no of stents used were 795 of different lengths $\&$ diameters. Length of the stents were 09 to $38 \mathrm{~mm}$ with mean of $16.5 \pm 9.8 \mathrm{~mm}$. Diameter of the stents used were 2.25, 2.5, 2.75, 3.0,

$3.5 \& 4.0 \mathrm{~mm}$ with a mean of $3.20 \pm 0.60 \mathrm{~mm}$ (Table-III). Angiographic success rate was $96 \%$ with procedural success $94 \%$ \& clinical success $92 \%$ (Table-IV). Failed PCI in 24 cases, 12 of them were chronic total occlusion, 5 were very tortuous angulated LCX, in 4 cases PTCA wire was negotiated but balloon didn't cross, in 3 cases wire crossed, balloon passed \& lesion dilated but no TIMI flow improvement, so considered as failed PTCA. 14 patients developed dissection, of which 12 required immediate intracoronary stents deployment \& other 2 improved by conservative treatment. Six patients developed slow flow \& treated with intracoronary diltiazem, adenosine \& nitrate \& overcome successfully (Table-V). Four patients developed acute LVF on the table \& were managed with IV nitrate, IV frusemide immediately. One patient died suddenly 2 hours after the procedure due to sudden arrhythmia and one patient died on the $4^{\text {t" }}$ day of procedure due to massive intraperitoneal hemorrhage causing irreversible shock $\&$ acute renal failure. Both these patients were female.

During the procedure of PCI in a pt. of double vessel disease (DVD), after deploying stents in LAD, same wire was passed to the LCX. After crossing the proximal part of the lesion wire was neither advancing forward, nor coming back. We tried to pull back the wire in different technique but all in vain. It was found that the tip of the wire has passed through the plaque into a small side branch. When we pulled it a bit strongly then the radiopaque portion of the wire is broken $\&$ remains within the coronary artery. Then we tried to withdraw the wire by introducing further two wires \& made intertwined with the broken wire but failed. Then we tried with coronary snare but also failed. Finally we crossed the lesion by a new wire \& dilated the lesion. After predilatation we implant a longer stent $2.5 \times 28$ to cross the lesion $\&$ entire portion of the broken wire was fixed with the wall. Total occlusion was 14.11 (Table-1). 30 Patients came back with the feature of new ischemia. They under went check CAG within 6 months of the procedure. Out of 40 patients 4 developed in-stent restenosis, which is approximately $10 \%$.

Table-I

Patient characteristics total number of the Patients: 600

\begin{tabular}{|c|c|}
\hline Characteristics & Number Percentage \\
\hline Age Range & $29-81$ yrs \\
\hline Mean & $50.5 \pm 8.69 \mathrm{yrs}$ \\
\hline Sex & Male: Female 11:1 \\
\hline
\end{tabular}

Risk Factors :

$\begin{array}{lll}\text { HTN } & 310 & 52 \% \\ \text { Smoker } & 426 & 71 \% \\ \text { DM } & 180 & 30 \% \\ \text { yperlipidemia } & 150 & 25 \% \\ \text { Positive family history } & 120 & 20 \%\end{array}$

Diagnosis (Clinical) :

1. Post MI angina $\quad 360$

Anterior MI with post MI angina $156 \quad 26 \%$

Inferior MI with post MI angina $204 \quad 34 \%$

2. Unstable angina without MI $240 \quad 40 \%$

Diagnosis (Angiographic):

1. Single vessel disease $\quad 312 \quad 52 \%$

2. Double vessel disease $\quad 156 \quad 26 \%$

3. Triple vessel disease $\quad 132 \quad 22 \%$

4. Total Occlusion $\quad 85 \quad 14.11 \%$ 
Table-II

Distribution of coronary artery lesions:

\begin{tabular}{lc}
\hline Parameter & Number \\
\hline No. Of target vessel & 760 \\
Total no. of lesions & 803 \\
Total no. of lesions treated & 780 \\
Plain PTCA & 34 \\
$\quad$ Mean vessel caliber & $3.05 \pm 0.71$ \\
Distribution of treated lesions & 780 \\
Left anterior descending (LAD) & 379 \\
$\quad$ Proximal LAD & 152 \\
Mid LAD & 175 \\
Distal LAD & 52 \\
Left circumflex (LCX) & 133 \\
Proximal LCX & 58 \\
Mid LCX & 53 \\
Distal LCX & 15 \\
LCX PD & 07 \\
Right coronary artery (RCA) & 226 \\
Proximal RCA & 93 \\
Mid RCA & 92 \\
Distal RCA & 24 \\
RCA PD & 17 \\
Obtuse marginal (OM) & 18 \\
Diagonal & 13 \\
Ramus intermedius & 11 \\
\hline
\end{tabular}

Table-III

Distribution \& Characteristics of stents used

\begin{tabular}{lc}
\hline Stent used: & Number \\
\hline Total no of stents: & 795 \\
Diameters of the stents: & \\
a) $2.25 \mathrm{~mm}$ & 25 \\
b) 2.5 & 147 \\
c) $2.75 \mathrm{~mm}$ & 87 \\
d) $3.0 \mathrm{~mm}$ & 345 \\
e) $3.5 \mathrm{~mm}$ & 185 \\
f) $4.0 \mathrm{~mm}$ & 06 \\
Mean & $3.10 \pm 0.61 \mathrm{~mm}$ \\
Lengths of the stents used: & \\
Range & $09-38 \mathrm{~mm}$ \\
$\quad$ Mean & $16.5 \pm 9.8 \mathrm{~mm}$ \\
\hline
\end{tabular}

Table-IV

Results of PCI

\begin{tabular}{lc}
\hline Result & No(\%) \\
\hline Angiographic success & $576(96 \%)$ \\
Procedural success & $564(94 \%)$ \\
Clinical success & $552(92 \%)$ \\
\hline
\end{tabular}

Table-V

Complications

\begin{tabular}{lc}
\hline Events & No(\%) \\
\hline Dissection requiring $2^{\text {nd }}$ stent & $12(2 \%)$ \\
Acute closure by flap dissection & \\
requiring $2^{\text {nd }}$ sent & $06(1 \%)$ \\
Acute closure by thrombus & $06(1 \%)$ \\
Acute Left ventricular failure & $04(1 \%)$ \\
Acute Myocardial infarction & $06(1 \%)$ \\
Failed PCI & $24(4 \%)$ \\
Mortality & $03(0.5 \%)$ \\
Wire broken & $01(0.2 \%)$ \\
Emergency CABG & $03(0.5 \%)$ \\
Stent Dislodgement & $02(0.4 \%)$ \\
Groin hematoma & $12(2 \%)$ \\
\hline
\end{tabular}

Table-VI

Distribution of Stents used in following vessels no. of stents 795

\begin{tabular}{lc}
\hline Vessel with location & Number \\
\hline LAD & 381
\end{tabular}

a) Proximal 156

b) Mid 176

c) Distal 49

LCX 145

a) Proximal 66

b) Mid 59

c) Distal 11

d) LCX PD 09

RCA 221

a) Proximal 95

b) Mid 92

c) Distal 19

d) RCA PD 15

OM 20

RI 10

Diagonal $\left(\mathrm{D}_{\mathrm{I}}\right)$ 


\section{TABLENO-VII RESULTS}

\begin{tabular}{lc}
\hline No of target vessel & 760 \\
No of target lesions & 803 \\
No of treated lesions & 780 \\
No of stents deployed & 795 \\
No of failed PCI & 24 \\
No of POBA & 34 \\
\hline
\end{tabular}

\section{Discussion:}

From our result it is found that in most of the indicated cases, PCI can be done efficiently with very minimum rate of failure $\&$ complication. In hospital mortality was only $0.50 \%$ with $1 \%$ periprocedural myocardial infraction and three emergency CABG- one case where stent dislodgment occurred, one was due to sub acute stent thrombosis and one was due to failed PCI. Thrombolytics in AMI can establish TIMI III flow in 40-60\% cases depending in the various regimens as well as the time duration of starting the thrombolytics from the onset of the symptoms. On the other hand if a patient can be taken to the catheter laboratory by 12 hours, primary angioplasty ${ }^{17,18}$, can achieve TIMI III flow in $80-90 \%$ of cases. Primary angioplasty is more effective than thrombolysis, with a significant lower risk of cerebral bleeding; better early patency rate leading to improved left ventricular function.

\section{A. Definitions of PCI Success}

A. The success of a PCI procedure may have the following components- angiographic success, procedural success $\&$ clinical success.

1. Angiographic success - A successful PCI produces substantial enlargement of the lumen at the target site. Previously definition was the achievement of a minimum stenosis diameter reduction to $<50 \%$ in the presence of grade 3 TIMI flow ${ }^{16}$. With the advent of advanced adjunct technology, including coronary stents, a minimum stenosis diameter reduction to $<20 \%$ has been the bench mark of an optimal angiographic result.

2. Procedural success- A successful PCI should achieve angiographic success without in-hospital major clinical complications e.g. death, Myocardial infarction, emergency coronary artery bypass surgery during hospitalization ${ }^{2,16}$.

3. Clinical success- clinically successful PCI includes anatomic \& procedural success with relief of signs \& or symptoms of myocardial ischemia after the patient recovers from the procedure.
B. Definitions of procedural complications According to the 1998 coronary interventional document (21) procedural complications are divided into six basic categories: death, MI, emergency CABG, Stroke, vascular access site complications \& contrast agent nephropathy.

C. Acute outcome: Despite the extension of coronary intervention to higher risk patients with co morbid disease \& complex coronary anatomy, angiographic $\&$ procedural success have increased since the first national heart lung \& blood institute (NHLBL) registries with an associated decrease in the major complications of Q-wave MI \& emergency CABG. Improvements in balloon technology coupled with the increased use of non-balloon devices, particularly stents \& glycoprotein II b/Ill a platelet receptor antagonist ${ }^{26-28}$ have favorably influenced acute procedural out come. This combined balloon with device \& pharmacological approach to coronary intervention in selective procedures has resulted in angiographic success rates of $96-99 \%$ with Q-wave MI rates of $1-3 \%$, emergency CABG rate 0.2 to $3 \%$ unadjusted in hospital mortality rates 0.5 to $1.4 \%$.

D. Long-Term outcome \& restenosis: The major obstruction of favorable long-term out come is restenosis. The pathogenesis of the restenosis is response to mechanical coronary injury thought to relate to a combination of growth factor stimulation, smooth muscle cell migration \& proliferation, organization of thrombus. Platelet deposition \& elastic recoil ${ }^{19,20,21 .}$ In addition dynamic change in vessel size or lack of complimentary enlargement has been implicated ${ }^{22}$. Definitions of restenosis at follow-up angiography have been most frequently used.

Other factors responsible for restenosis are clinical conditions like DM unstable angina, acute MI prior restenosis $^{22-23}$, angiographic factors like proximal left anterior descending artery, small vessel diameters, total occlusion; long lesion length, $\mathrm{SVG}^{29}$ \& the procedural factors e.g.: higher post procedure percent diameter, bifurcation lesion, smaller acute gain ${ }^{30}$ have been associated with an increased incidence of restenosis. Recently developed drug coated stents have reduced the incidence of restenosis drastically to $0-4 \%$. Ten years follow up of initial cohort of patients treated with PTCA revealed $89.5 \%$ survival rate $(95 \%$ with single vessel disease, $81 \%$ in patients with multivessel disease ${ }^{25}$. In patients undergoing with the 1985-1986 NHLBL PTCA registry ${ }^{30}$ a five year survival was $92.9 \%$ for patients with 
single vessel disease, $88.5 \%$ for double vessel disease $\&$ $86.5 \%$ for triple vessel disease. In patients with multivessel disease undergoing PTCA in BAR 1, a 5-year survival was $86.3 \%$, infarct free survival was $78.7 \%$. Specifically 5 -year survival was $84.7 \%$ with TVD, $87.6 \%$ with DVD (Double vessel disease). With the advent of novel drug eluting stents the indication of PCI has changed. Now a days randomly PCI done to Left main coronary artery, osteal lesions bifurcation lesions, multivessel diseases, complex lesions. The result is also favourable. Though in our setting there is some lack of logistic support like intra aortic balloon pump (IABP), intravascular ultrasound (IVUS) so we are, a bit behind which is the real scenario, even in this context we are doing PCI well with Complex lesions, bifurcation lesions, Ostial lesions. Hopefully within short time we shall not remain behind in the field of PCI with developed countries.

\section{Conclusion:}

In the field of management of coronary artery disease percutaneous coronary intervention (PCI) is the internationally recognized standard treatment worldwide for near about 3 decades. Our result of PCI correlates well with the other studies worldwide, though the study population is small \& there are many lacks of logistics in our country. However the additional iatrogenic mechanical injury to coronary atherosclerosis initiate a new disease process restenosis in a few cases approximately $10-15 \%$, though with the advent of drug coated stents like sirolimous coated BX velocity balloon expandable stent $\&$ paclitaxel-eluting stents has overcome the major adverse effect like restenosis. Though these stents are very costly for our developing country, but hope that in near future it will come within our reach. These stents can give only the benefit of preventing in stent restenosis leaving the remaining entire coronary systems to atherosclerosis. So it should be a combined duty of interventionist \& patients to prevent occurrence of further coronary artery lesion including the life style modification, strict control of HTN, DM, and SMOKING. Modifiable risk factor control is one of the important fates of success of intervention.

\section{References}

1. Gruesntzig AR, Senning A, Siegenthaler WE. Nonoperative dilation of coronary artery stenosis: percutaneous transluminal coronary angioplasty. N Eng J Med 1979; 301: 61-8.

2. Kent KM, Bentivoglio LG, Block PC, et al. Percutaneous transluminal coronary angioplasty report from the Registry of the National Heart, Lung and Blood Institute. Am J Cardiol 1982; 49: 2011-20.

3. Williams DO, Rilely RS, Singh AK, Most AS. Restoration of normal coronary hemodynamics and myocardial metabolism after percutaneous translumial coronary angioplasty. Circulation 1980; 62: 653-6.

4. Miller DD, Veram MS. Current status of myocardial perfusion imaging after percutaneous tansluminal coronary angioplasty. J Am Coll Cardiol 1994; 24: 260-6.

5. Detre KM, Holmes DR, Jr, Holubkov R, et al. Incidence and consequences of periprocedural occlusion: the 1985-1986 National Heart, Lung and Blood Institute. Percutaneous Transluminal Coronary Angioplasty Registry. Circulation 1990; 82: 739-50.

6. Detre KM, Holubkov R, Kelsey S, et al. Percutaneous transluminal coronary angioplasty in 1985-1986 and 1971981: The National Heart, Lung and Blood Institute Registry. N Eng J Med 1983; 318: 265-70.

7. O'Keefe JH, Jr, Rutherford BD, McConahay DR, et al. Multivessel coronary angioplasty from 1980 to 1989: procedural results and long-term outcome. J Am Coll Cardiol 1990; 16: 1097-102.

8. American Heart Association. 2001 Heart and Stroke Statistical update. Dallas, TX; American Heart Association, 2001.

9. Comparison of coronary bypass surgery with angioplasty in patients with multivessel disease: The Bypass Angioplasty Revascularization Investigation (BARI) Investigators. [Published erratum appears in N Engl J Med 1997; 336: 147.] N Eng J Med 1996; 335: 217-25.

10. Coronary angioplasty versus coronary artery bypass surgery: the Randomized Intervention Treatment of Angina (RITA) trial. Lancet 1993; 341: 573-80.

11. Kings SB, III, Lembo NJ, Weintraub WS et al. A randomized trial comparing coronary angioplasty with coronary bypass surgery: Emory Angioplasty versus Surgery Trial (EAST). N Engl J Med 1994; 331: 1044-50.

12. Hamm CW, Reimers J, Ischinger T, Rupprecht HJ, Berger J, Bleifeld W. A randomized study of coronary angioplasty compared with bypass surgery in patients with symptoimatic multivessel coronary disease: German Angioplasty Bypass Surgery Investigation (GABI). N Engl J Med 1994; 331: 103743.

13. Rodriguez A, Boullon F, Perez-Balino N, et al. Argentine randomized trial of percutaneous transluminal coronary angioplasty versus coronary artery bypass surgery in multivessel disease (ERACI): in-hospital results and 1-year follow-up. J Am Coll Cardiol 1993; 22: 1060.

14. Pocock SJ, Hendersom RA, Riockards AF, et al. Meta-analysis of randomized trials comparing coronary angioplasty with bypass surgery. Lancet 1995; 346: 1184-9.

15. American College of Cardiology- National Cardiovascular Data Registry Version 2.0. American College of Cardiology Website. Available at:http://www.acc.or!-'/ncdr/catlilab.htm. Accessed April 4, 2001.

16. Guidelines for percutaneous transluminal coronary angioplasty: a report of the American College of Cardiology/American Heart Association Task Force on Assessment of Diagnostic and Therapeutic Cardiovascular Procedures (Committee no Percutaneous Transluminal Coronary Angioplasty). J Am Coll Cardiol 1993; 22: 2033-54. 
17. Detre KM, Wright E, Murphy ML, Takaro T. Observer agreement in evaluating coronary angiograms. Circulation 1975; 52: 979-86.

18. Brown BG, Bolson EL, Dodge HT, Quantitative computer techniques for analyzing coronary arteriograms. Prog Cardiovasc Dis 1986: 28: 403-18.

19. Roubin GS, Cannon AD, Agrawal SK, et al. Intracoronary stenting for acute and threatened closure complicating percutaneous transluminal coronary angioplasty. Circulation 1992; 85: 916-27.

20. Mark DB, Talley JD, Topol EJ, et al. Econimic assessment of platelet glycoprotein IIb/IIIa inhibition for prevention of ischaemic complications of high-risk coronary angioplasty. EPIC Investigators. Circulation 1996; 94: 629-35.

21. Platelet glycoprotein IIb/IIIa receptor blockade and low-dose heparin during percutaneous coronary revascularization: the EPILOG Investigators. N Engl Med 1997; 336: 1689-96.

22. Randomized placebo-controlled and balloon-angioplastycontrolled trial to assess safety of coronary stenting with use of platelet glycoprotein IIb/IIIa blockade. The EPISTENT Investigators. Evaluation of Platelet IIb/IIIa Inhibitor for Stenting. Lancet 1998; 352: 87-92.

23. Ellis SG, Cowley MJ, Whitlow PL, et al. Prospective casecontrol comparison of percutaneous transluminal coronary revascularization in patients with multivessel disesse treated in 1986-1987 versus 1991: improved in-hospital and 12 month results. Multivessel Angioplasty Prognosis Study (MAPS) Group. J Am Cold Cardiol 1995; 25: 1137-42.
24. Leon MB, Balm DS, Popma JJ, et al. A Clinical trial comparing the antithrombotic drug regimens after coronary artery stenting. Stent Anticoagulation Restenosis Study Investigators. N Engl J Med 1998; 339: 1665-71.

25. Fischman DL, Leon MB, Balm Ds, et al. A randomized comparison of coronary stent placement and balloon angioplasty in the treatment of coronary artery disease: Stent Restenosis Study Investigators. N Engl Med 1994; 331: 496501 .

26. Serruys PW, de Jaegere P, Kiemeneij F, et al. A comparison of balloon-expandable-stent implantation with balloon angioplasty in patients with coronary artery disease: Benestent Study Group. N Engl J Med 1994; 331: 489-95.

27. Fishman NW, Kennard Ed, Steenkiste AR, Popma JJ, Baim DS, Detre KM. New Approaches to coronary Intervention (NACI) registry: history and methods. Am J Cardiol 1997; 80: 1 OK-8K.

28. Baim DS, Cutlip DE, Sharma SK, et al. Final results of the Balloon vs. Optimal Atherectomy Trial (BOAT). Circulation 1998; 97: 322-3 1 .

29. King SB, III. Ten-year completed follow-up of percutaneous transluminal coronary angioplasty: the eaary Zurich experience. J Am Coll Cardiol 1996; 22: 353-60.

30. Holmes DR, Jr. Kip KE, Kelsey SF, Detre KM, Rose n AD. Cause of death analysis in the Nhlbi Ptca Regitry: results and considerations' for evaluating long-term survival after coronary interventions. J Am Coll Cardiol 1997; 30: 881-7. 